\title{
El Uso de la Tecnología 3D en televisión, ¿cuestión de continente o de contenido?
}

\begin{abstract}
Resumen
En este estudio, vamos a realizar un repaso por la tecnología 3D y su uso en emisiones (para aquellos que tienen la tecnología que hace posible), el potencial de esta nueva tecnología y si es realmente un valor ańadido al producto final, es decir, si cambian las formas de contar las cosas o se trata simplemente de un campo de negocios más. Habrá que ver si es rentable o no. Si bien esto es todavía una tecnología incipiente en la televisión, con la llegada del 3D, el creador de productos televisivos deberá intentar aportar un valor ańadido a su programación.
\end{abstract}

Palabras clave: Tecnología 3D, Televisión, Formas de contar, Valor añadido, Cine.

\section{The Use of 3D Technology on Tv Continent or Content Matter?}

\begin{abstract}
This study conducts a quick review of 3D Technology and its use in broadcasting (for those who have this technology), the potential of this new technology and the consideration whether it is really a value added for the final product; i.e. if it changes the ways of telling things or it is another business field. We will have to evaluate whether it is profitable or not. Although it is still an incipient technology in television, with the arrival of 3D Technology, television products creator should try to generate a value added for his programming.

Key words: 3D Technology, Television, the way of telling, added value, Cinema

Dra. Aránzazu Román San

Miguel

Doctora en periodismo

Universidad de Sevilla, España
\end{abstract}




\section{Introducción. Tecnología 3D y panorama audiovisual hoy}

En los últimos tiempos, el cine ha visto mermar sus ingresos a causa, sobre todo, de las descargas ilegales a través de la red y el auge del ocio doméstico en general, además de una crisis de ideas en la elaboración de guiones originales.

Como en otros momentos de la historia del cine, la industria ha tenido que reinventarse para generar un llamado hacia las salas y, por qué no, para idear nuevos modos de transmisión más difíciles de copiar, volviendo a una tecnología nada nueva, pero sí renovada: el 3D.

La televisión ha ido avanzando tras el cine en sus formas de contar y también en la tecnología para transmitir aquello que se cuenta. Por ello, no ajena a los avances tecnológicos, necesita competir en el ámbito del entretenimiento para mantener también su cuota de pantalla. Es por ello que, poco a poco, está adaptando también esa renovada tecnología tridimensional para sus emisiones. Si bien se trata aún de una tecnología en ciernes en el ámbito televisivo, con la llegada de los televisores en 3D los creadores de productos televisivos se plantean otorgar este valor añadido a su programación. Sin duda el punto de inflexión lo ha marcado la emisión de parte de los Juegos Olímpicos de Londres en 3D por parte de la $\mathrm{BBC}$, según se ha comprometido. La BBC emitió los Juegos Olímpicos de Londres 2012 en 3D (SatCesc.com, 2012) ${ }^{1}$.

De hecho, el 14 de agosto de 2012, la Vanguardia publicaba una información titulada: Los Juegos Olímpicos de Londres, aliados con la última tecnología, aunque ya veremos que no trata de una tecnología nueva ni mucho menos, aunque sí de una tecnología mejorada. Y en el cuerpo de texto podíamos leer:

Por primera vez en la historia se han podido ver los Juegos Olímpicos en tres dimensiones, gracias a las videocámaras AG3DP1 y AG-3DA1 de Panasonic. La marca, proveedora oficial de audio y vídeo de la competición desde Seúl'88, cubrió con la nueva tecnología grandes eventos de los juegos como las galas de

1 (...) La cobertura 3D de los Juegos Olímpicos de Londres 2012 se transmitió a través del canal $\mathrm{BBC} \mathrm{HD}$, disponible en abierto a través de la posición orbital de 28,20 Este de Astra 
inauguración y clausura o las pruebas de atletismo, natación y gimnasia. En total se ofreció una cobertura en 3D de más de 200 horas. Y así, los espectadores que no pudieron asistir lo vieron en sus televisores de la forma más real que la tecnología permite. Mientras cadenas como Eurosport, BBC o NBC Oympics retransmitían las imágenes en casa, Panasonic lo hacía en los monitores de televisión de tres dimensiones instalados en la zona olímpica. (Lavanguardia.es, 2012).

Como vemos, las marcas productoras y distribuidoras de tecnología han tenido en la implantación de la tecnología 3D y su puesta en práctica en los Juegos Olímpicos de Londres 2012, una fuerte presencia publicitaria gratuita y de calidad en los medios de comunicación. De hecho, parece ser que el número de receptores se incrementó por este evento y se prevé que vaya en alza en los próximos años:

Con la primera ronda de aparatos con capacidad 3D llegando a los establecimientos y los planes de los fabricantes de televisores de lanzar más productos al mercado en breve, Display Search ha aumentado su previsión de ventas de televisores 3D para 2010 y los próximos ańos. Ahora la consultora prevé que la cifra de unidades vendidas rondará los 2,5 millones este ańo y que alcanzará los 27 millones en 2013.

(...)

Finalmente, DisplaySearch señala que, aunque se pronostica que la tecnología 3D mostrará un rápido crecimiento, sólo el 27 por ciento de los aparatos de $\mathbf{4 0}$ pulgadas o más que se suministrarán en 2013 dispondrán de capacidad 3D. (Gómez, H., 2010).

Por su parte, TerraTV retransmitió a través de su página web algunas competiciones olímpicas en 3D, todavía hoy pueden visionarse algunas hazañas como la de la holandesa Ranomi en natación (Terra, 2012).

Aunque ya en julio de 2011 en España, Televisión Española anunciaba que iba a realizar una prueba técnica en 3D. "Este lunes Televisión Española realizará la primera prueba, a nivel nacional y en abierto, de la 
emisión de un programa en 3 dimensiones. Será una actuación del grupo de rap 'Violadores de verso' rodado hace unas semanas. Podrán disfrutar de ella quienes dispongan de un receptor con esta tecnología y usando las gafas para contenidos tridimensionales". (Prensa RTVE, 2011).

En Espańa, aunque TVE tiene los derechos para retransmitir en 3D, los españoles no pudimos seguir los Juegos Olímpicos de Londres 2012 en tres dimensiones a través de la cadena pública, debido a los recortes que se han producido en el ente público como consecuencia de la crisis económica que atraviesa el país. (ADSL ZONE, 2012) ${ }^{2}$. No obstante, los amantes del deporte tendrán la posibilidad de visionar el acontecimiento deportivo más importante a nivel mundial, en 3D a través de la red, puesto que Terra, de la multinacional espańola Telefónica ha anunciado que los retransmitirá on-line (EFE, 2012) ${ }^{3}$.

Del mismo modo, se pudieron ver a través de TVE los Juegos Olímpicos en 3D, gracias a la televisión Cinema 3D Smart TV, convirtiendo los contenidos de 2D a 3D pulsando un botón (lgblog, 2012). Como vemos, las compañías de tecnología no han parado de

${ }^{2}$ De momento, en España no se podrán ver los Juegos Olímpicos de Londres en 3D. En el Reino Unido han preparado una gran cobertura, con cientos de horas de emisión de contenidos en 3D en torno a los Juegos Olímpicos que se celebran este verano. Televisión Española (TVE) dispone de los derechos de retransmisión también en $3 \mathrm{D}$, pero su situación interna y los recortes no invitan al optimismo: en el ente público, no hay planes, al menos de momento, para ofrecer una señal 3D de los Juegos Olímpicos.

3 El portal Terra, de la multinacional española Telefónica, presentó hoy en Sao Paulo la plataforma para la cobertura de los Juegos Olímpicos de Londres, evento que tendrá por primera vez transmisiones en tercera dimensión (3D) por internet. (...) el portal tendrá 36 canales simultáneos de transmisiones en vivo de la competencia que se celebrará entre el 27 de julio y el 12 de agosto en la capital británica.

"Será la primera vez que unos Juegos Olímpicos tendrán transmisión en 3D en la red y la primera vez que un portal tendrá un estudio montado en el centro de prensa”, señaló Castro.

(...) serán 4.760 horas de transmisión con imágenes de alta definición en ediciones separadas en español y portugués, con una cobertura en 17 países y una plataforma de multimedia específica para computadores, teléfonos móviles, tabletas electrónicas y televisores conectados a la red de internet 
hacerse publicidad para que los ciudadanos adquieran tecnología 3D. En este mismo sentido, Eurosport también retransmitió en 3D, aunque de pago para los abonados de Sky. (ADSL ZONE, 2012) .

Como vemos, el 3D se está implantando en el ámbito deportivo, un contenido audiovisual que ofrece gran espectáculo, y es que el espectador necesita contenidos espectaculares para que le merezca la pena el esfuerzo que tiene que hacer a la hora del visionado en tres dimensiones.

Pero, ¿a qué llamamos 3D? Hablemos un poco de ello.

\section{La visión 3D}

En la creación audiovisual, se han etiquetado como "3D" a distintas técnicas, y es que este término se ha usado para aquella disciplina que a través de programación informática genera elementos con profundidad y perspectiva, películas de animación como "Toy Story" usan este tipo de tecnología. Pero también el término "3D" se usa para la producción y visualización de contenidos que aprovechan la peculiaridad binocular de la visión humana o estereopsis. El objeto de nuestro estudio será esta última técnica, llamada 3D estereoscópica, aplicada al mundo de la televisión.

En efecto, el ser humano tiene una visión binocular, vemos a través de dos ojos, el sistema visual genera dos imágenes ligeramente diferentes por cada ojo debido a la separación entre ambos de $6.5 \mathrm{~cm}$. Gracias a esta separación el cerebro recibe dos señales ligeramente desfasadas y es la interpretación de este desfase por el cerebro lo que provoca que captemos la profundidad de la realidad que tenemos ante nosotros.

Así, si tomamos o creamos dos imágenes con un ángulo ligeramente distinto y se las mostramos a cada ojo por separado, el cerebro podrá reconstruir la distancia y por lo tanto la sensación de profundidad. En

${ }^{4}$ Eurosport 3D ofrecerá una amplia cobertura de los Juegos Olímpicos 2012. El canal paneuropeo ha presentado su cobertura para este importante evento deportivo que podrán seguir los abonados de Sky. En total, más de 100 horas dedicadas a los Juegos Olímpicos de Londres se podrán seguir en formato estereoscópico.

(...) Las retransmisiones estarán disponibles a través de la frecuencia del canal Sky $3 \mathrm{D}$. 
este "sencillo" principio se basan todas las técnicas de producción 3D estereoscópica. La estereoscopía no hace sino emular el modo en que el cerebro humano percibe la tridimensionalidad basándose en un par de imágenes planas proporcionadas por las dos retinas.

Ahora bien, la sensación de profundidad que proporcionan las imágenes estereoscópicas no es siempre la misma, sino que depende de distintos factores:

-Distancia observador-imagen.

La sensación de profundidad aumenta con la distancia al observador. Aunque esta afirmación puede parecer falsa, lo cierto es que al alejarnos de la imagen la importancia relativa del ángulo de paralaje adquiere mayor importancia; así, el objeto parece que tiene mayor espesor.

-Distancia entre las imágenes que componen el estereograma.

A mayor separación entre las imágenes, mayor volumen aparente de los objetos. El cerebro debe de esforzarse más para lograr la convergencia de las imágenes.

-Distancia entre las tomas de las dos fotografías.

A mayor separación entre los dos puntos de vista, mayor sensación de volumen.

-Distancia focal del objetivo de la cámara.

Una focal mayor produce una sensación de relieve menor aunque en efecto estéreo, para un mismo objeto y a la misma distancia, es más pronunciado con longitudes focales largas.

-Distancia de la cámara a la escena reproducida.

A mayor distancia a la escena, menos es el efecto estéreo. (Castillo, J.M., 2011:44-45)

\section{Un poco de historia}

Cuando hablamos de tecnología 3D debemos tener en cuenta que no estamos ante un fenómeno nuevo, sino que se trata de algo que ya existía pero que ahora se ha puesto de moda (Onural, L. y Ozaktas H.M. 
2008:1) $)^{5}$. Las industrias del cine y la televisión han traído a la actualidad esta tecnología para vender de otro modo y superar así la crisis en el sector de la imagen.

Muchos espectadores del "Avatar" de Cameron salieron de la sala convencidos de haber asistido a una exhibición de la última tecnología de la imagen. Esto es cierto solo en una parte, la de la tecnología aplicada. Lo que ignoran es que la estereoscopía es muy anterior a la aparición del cine y de la propia fotografía.

Ya en el siglo XVI, Giovanni Battista della Porta realizó dibujos binoculares y Jacopo Chimenti da Empoli realizó dibujos similares uno al lado del otro, era obvio que conocían la visión binocular humana.

Habría que esperar hasta 1838 para la invención del estereoscopio, Charles Wheatstone inventó el primer aparato con el que se podían apreciar dibujos geométricos. La primera cámara fotográfica estereoscópica se atribuye a David Brewster, en 1849, y Olivier Wendell Homes es quien construyó en 1862 un modelo de visor de fotografías tridimensionales que terminó siendo muy popular en el último cuarto del siglo XIX. Las más de 10.000 imágenes tridimensionales que llegaron a ofrecer distintas empresas norteamericanas entre 1885 y 1935 nos dan una idea de la magnitud del negocio y el interés del público.

En el cine, tras algunos experimentos hacia 1872, se conocen proyecciones en $3 \mathrm{D}$ en el Teatro Astor de Nueva York, donde se mostraban una serie de cortometrajes sobre las cataratas del Niágara, escenas rurales del país, etc.

En 1922, se presentó el primer largometraje de ficción en 3D, Elpoder del amor (Nat C. Deverich) y posteriormente Radiomania (William Neil, 1922). Según las crónicas de la época, tuvieron poco reconocimiento de público y crítica. No será hasta 1952 con el estreno de Bwana, el diablo

5 3D photography, cinema, and TV actually have a long history; in fact, stereoscopic $3 \mathrm{D}$ versions of these common visual media are almost as old as their $2 \mathrm{D}$ counterparts. Stereoscopic 3D photography was invented as early as 1839 . The first examples of 3D cinema were available in the early 1900s. Various forms of early $2 \mathrm{D}$ television were developed in the 1920s and by 1929 , stereoscopic 3DTV was demonstrated. 
de la selva (Arch Oboler) y algunas películas más, entre las que se incluye Crimen Perfecto (Hitchcock, 1954), cuando exista un pequeño auge de la producción de películas en $3 \mathrm{D}$.

Técnicamente, el invento de Wheatstone no podía usarse en salas de cine, solo lo podría utilizar un único observador situado en una posición concreta. Para la proyección pública, se han desarrollado distintas técnicas para enviar a cada ojo imágenes diferentes.

Las primeras películas estereoscópicas hacían uso de una técnica basada en el color. Cada espectador usaba unas gafas especiales (anaglíficas) relativamente baratas donde cada ojo se cubría con un celofán semitransparente de distinto color, rojo y azul. La película consistía en una superposición de dos imágenes, con las porciones que deben ser vistas por uno u otro ojo del color opuesto al del celofán. Así, cada ojo recibe la imagen que le corresponde. Se transmitía una sensación $3 \mathrm{D}$ relativamente buena y que podía ser usada en televisión usando las mismas gafas. Era un sistema barato aunque producía muchos mareos.

La incorporación del cine digital y la consiguiente adaptación de las salas abrió un nuevo abanico de posibilidades tecnológicas, es un proceso en continua evolución donde la electrónica avanza posibilitando mayores resoluciones y velocidades; así, es necesario mantener la calidad de visionado al mismo tiempo que somos capaces de emitir el doble de imágenes por segundo.

Stereoscopic 3D, whether in its conventional form as in the old stereoscopic cinema, or in its more modern forms involving autostereoscopic systems, falls far from the vision of true optical replicas that have been outlined at the beginning of this chapter. To circumvent the many problems and shortcomings of stereoscopy in a radical manner, it seems necessary to abandon the basic binocular basis of stereoscopy, and by turning to basic physical principles, to focus on the goal of true optical reconstruction of optical wave fields. Optically sensitive devices, including cameras and human eyes, do not "reach out" to the environment or the objects in them; they merely register the light incident on them. The light registered by our eyes, which carries the information about the scene, is 
processed by our visual system and brain, and thus we perceive our environment. Therefore, if the light field which fills a given $3 \mathrm{D}$ region can be recorded with all its physical attributes, and then recreated from the recording in the absence of the original object or scene, any optical device or our eyes embedded in this recreated light field will "see" the original scene, since the light incident on the device or our eyes will be essentially indistinguishable in both cases. This is the basic principle of holography, which is a technique known since 1948. Holography is distinct from ordinary photography in that it involves recording the entire optical field, with all its attributes, rather than merely its intensity or projection ("holo" in holography refers to recording of the "whole" field). As expected, the quality of the holographic recording and reconstruction process will directly affect the fidelity of the created ghostlike images to their originals. Digital holography and holographic cinema and TV are still in their infancy. However, advances in optical technology and computing power have brought us to the point where we can seriously consider making this technology a reality. It seems highly likely that high quality $3 \mathrm{D}$ viewing will be possible as the underlying optics and electronics technologies mature. (Onural, L. y Ozaktas H.M. 2008: 3-4).

Del mismo modo, traduciendo las palabras de Onural y Ozaktas, es útil tener en cuenta la distinción entre las pantallas 3D y 3D televisión (3DTV). Usamos el término 3D para referirnos a dispositivos de imagen que crean percepción 3D en la salida de la imagen. 3DTV se refiere a toda la cadena de adquisición de imágenes 3D, codificación, transporte/ difusión, recepción, así como visionado. Hasta ahora, se ha discutido sobre el visionado final de la tecnología 3DTV. Un sistema de principio a fin, 3DTV requiere no solo mostrar, sino también capturar y transmitir contenido 3D. Algunos significados de 3D ya llevaban implícita la discusión del visionado. Por ejemplo, el 3DTV estereoscópico consiste en una cámara estereoscópica, que no es más que dos cámaras montadas de forma fija una al lado de la otra con una separación apropiada. (Onural, L. y Ozaktas H.M. 2008: 4). 
Aunque el objetivo final de nuestro trabajo es la Televisión 3D, vamos a hacer un pequeño repaso por las técnicas usadas en el cine, y es que el séptimo arte es el laboratorio de muchas tecnologías televisivas.

El mercado de cámaras y sistemas para la captación de imágenes 3D evoluciona constantemente. La colocación de las cámaras, la adaptabilidad a los distintos formatos, la aparatosidad del conjunto... son parámetros a tener en cuenta en la producción audiovisual.

Veamos algunos ejemplos de cámaras usadas en el entorno cinematográfico en 3D:

- StereoSpace, desarrollado para United Artist consiste en la sincronización de dos cámaras Mitchell de $65 \mathrm{~mm}$ situadas con una separación de $90^{\circ}$ entre sí, filmando a través de un semiespejo de $45^{\circ}$ una de ellas, y otra filmando por reflexión de dicho espejo.

- Imax 3D utiliza dos tipos de cámaras. La primera sitúa una cámara sobre la otra formando un ángulo de $90^{\circ}$ entre sí. La cámara superior está orientada hacia el suelo y obtiene la imagen a través de un espejo que está situado a $45^{\circ}$. Este espejo refleja un $50 \%$ de la imagen y deja pasar otro $50 \%$ de la imagen, que es recogida por la cámara inferior. El otro tipo de cámara, denominada Solido camera, utiliza una cámara con dos objetivos separados $64 \mathrm{~mm}$. Un sistema de espejos internos permiten que cada objetivo registre una imagen diferente en un rollo de película.

- Stereocam es una plataforma sobre la que se instalan dos cámaras y se utiliza un espejo semirreflectante. Este sistema permite ser usado por una gran cantidad de cámaras, permitiendo corregir la distancia interaxial y la distancia de convergencia.

- Pace Fusión 3D, la cámara con la que se rodó "Avatar" está compuesta por dos cuerpos de cámara Sony T950 modificados para lograr adaptarse a una separación interocular de $70 \mathrm{~mm}$ y a las ópticas Fujinon y Panavisión. Es relativamente ligera, y con sucesivos perfeccionamientos ha sido usada para "Torrente 4" (Santiago Segura, 2011), Transformers: Dark Side of the Moon" 
(Michael Bay, 2011) o "Hugo" (Martin Scorsese, 2011). Además de distintos eventos musicales y deportivos como la gira de U2 3D o la Super Bowl. (Armenteros, M, 2011:2-4).

Como en muchos ámbitos, la innovación tecnológica es un valor ańadido a las empresas del sector, y, en el campo audiovisual, el cine, y en mayor medida la televisión, son un magnífico escaparate para el marketing de las grandes multinacionales del sector: Panasonic, Sony, JVC son los principales proveedores de tecnología al servicio de la producción de televisión. Pero también extienden su influencia sobre el mercado doméstico; todas han desarrollado cámaras domésticas de 3D.

En los Juegos Olímpicos de Londres 2012, según Panasonic:

Junto a las más de 300 cámaras que cubren los Juegos en alta definición 2D, Londres 2012 cuenta con una treintena de cámaras ENG en 3D, una veintena de rigs estereoscópicos y hasta tres unidades móviles 3D que OBS ha desplegado para llevar a todo el mundo este acontecimiento en tres dimensiones.

Los camcorders que se utilizarán serán los P2HD AG-3DP1, de doble lente y grabación sobre tarjetas de memoria de estado sólido. Dando a poyo a estas cámaras encontramos también las ligeras AG3DA1 que están permitiendo ofrecer imágenes en 3D con total flexibilidad y agilidad en la captación.

En EE. UU., las más de 300 horas de contenidos en 3D se están transmitiendo desde el IBC de Londres al Comcast Media Center en Colorado distribuyendo desde ahí la señal a redes como DirecTV, Time Warner Cable o Cablevision.

Lo mismo está ocurriendo en las regiones en todo el mundo, de Europa y Asia a América del Sur. Cerca de 12 horas de programación en 3D se están produciendo a diario, con las pruebas más destacadas y resúmenes con los mejores momentos.

Pero la 3Dmanía no solo está invadiendo los hogares ya que en numerosos lugares, principalmente en Reino Unido, los Juegos en 3D están siguiéndose desde establecimientos públicos. Incluso, 
podemos encontrar bares que regalan la preceptiva gafa $3 \mathrm{D}$ al consumir varias pintas de cerveza...

Según estimaciones de Panasonic, alrededor de un millón de personas están siguiendo los juegos en 3D en todo el mundo. (Panoramaaudiovisual.com, 2012).

A estas marcas, hay que añadir otras que se han centrado en el desarrollo de televisiones: Samsung, LG, Philips, Toshiba... han colocado en el mercado un gran número de pantallas con capacidad de visionado de contenido $3 \mathrm{D}$ y algunas con conversores $2 \mathrm{D}->3 \mathrm{D}$, que simulan la tridimensionalidad de cualquier contenido.

Entender que, prácticamente, todo el sector audiovisual, profesional y doméstico está copado por unas pocas empresas, nos mostrará las líneas de interés del gran negocio de la producción. Es obvio que estas grandes empresas usan como escaparate grandes eventos, deportivos y musicales sobre todo, para anunciarse como proveedores también en el sector doméstico, veamos un ejemplo:

Panasonic, patrocinador de Roland-Garros 2011 ha anunciado que el Open de Tenis de Francia, el Roland Garros, será retransmitido en directo y en 3D en más de 17 países en toda Europa (excepto Francia*) en colaboración con Eurosport, lo que lo convierte en uno de los eventos deportivos disponible en $3 \mathrm{D}$ en miles de hogares. La retransmisión en 3D también será una realidad en Francia a través del acuerdo con Orange.

La multinacional japonesa dotó de varios equipos 3D para la retransmisión de Roland Garros: el camcorder AG-3DA1, un sistema de rig side-by-side con dos cámaras AK-HC1800, seis conmutadores de directo multiformato AV-HS450, tarjetas de memoria P2, monitores de producción 3D BT-3DL2550 de 25" y el monitor de 9" BT-LH910.

El compromiso de Panasonic con la innovación de los productos de entretenimiento para el hogar también se exhibirá en el evento, ya que la empresa realizará la primera demostración de TV en 3D 
retransmitida por banda ancha (HbbTV). El 3D HbbTV es un importante paso adelante para la revolución 3D, ya que permite al usuario ver contenidos en $3 \mathrm{D}$ del mismo modo que los contenidos de TV en 2D usando servicios de catch-up TV a través de televisores con posibilidad de conexión a Internet o set-top boxes.

HbbTV es una nueva iniciativa pan-europea con el objetivo de armonizar la emisión y entrega de banda ancha de servicios de entretenimiento, para ayudar al consumidor a gestionar con eficacia la cada vez mayor cantidad de contenidos de TV a su disposición. Las especificaciones de la HbbTV han sido desarrolladas por los líderes de la industria y están siendo utilizadas por Panasonic para darle al público más oportunidades de ver contenido en $3 \mathrm{D}$.

En España, los aficionados al tenis que todavía no disponen de un televisor $3 \mathrm{D}$ podrán disfrutar en directo del evento en 30 puntos de venta ubicados por todo el territorio español. En las diferentes tiendas se podrá disfrutar del Roland Garros en 3D en los espacios Panasonic disponibles. En la página web de Panasonic se pueden consultar los puntos de venta. (Nota de prensa Panasonic).

Como vemos, Panasonic habla de gran cantidad de contenidos, pero no de un cambio sustancial de los mismos. Si en el ámbito de la televisión hablamos de una "guerra" por la audiencia, de esta saldrán victoriosas las empresas televisivas que sean capaces, no solo de realizar el desembolso económico necesario para adaptarse a las nuevas tecnologías, sino quienes sean capaces de crear contenidos específicamente diseñados para los nuevos formatos. De hecho, volviendo al cine, hemos oído hablar a cantidad de críticos cinematográficos de que el secreto de la película "Avatar" ha estado en el 3D, pues este film en 2D hubiera sido un fracaso rotundo. No sabemos cuánto de verdad hay en ello, lo que sí sabemos es que un cambio en la tecnología debe llevar emparejado un cambio en el modo de contar las cosas, si no, tendremos más de lo mismo y el espectador buscará nuevos contenidos en otras plataformas más cómodas. 


\section{Uso potencial de la tecnología 3D en televisión}

Ozaktas se hace esta pregunta: Will commercial three-dimensional television replace two-dimensional television, or will it remain as a novelty limited to only a certain fraction of consumers? A lo que responde diciendo que es iluso creer que la tecnología 3D se impondrá en la televisión a color.

Es importante entender la aceptación de las nuevas tecnologías en el contexto de la competencia entre las fuerzas rivales del mercado. D. Kaya- Mutlu contó que en la década de 1950, cuando la televisión se había convertido en una seria alternativa al cine, la Industria cinematográfica estadounidense presentó las novedades tecnológicas para atraer a los espectadores de teatro a las salas de cine. La primera novedad era el cine en $3 \mathrm{D}$ pero no tuvo un impacto duradero en los espectadores. Las gafas especiales que se requieren fueron la principal razón para la resistencia de la audiencia. Esto es por lo que muchos investigadores consideramos que es importante desarrollar métodos que no requieren el uso de dicho equipo. La siguiente novedad era el Cinerama, que creó una ilusión de tridimensionalidad sin gafas especiales. Se obtuvo mayor interés del público, pero también se convirtió en una atracción turística en algunos lugares, probablemente debido a que requiere un entorno de exposición diferente y complejo. Finalmente, fue el proceso de gran angular, Cinemascope, presentado por el XX Century Fox en 1953, el que tuvo el efecto más duradero entre estas novedades. Películas Cinemascope ofrecían una imagen de pantalla ancha con el color y sonido estéreo, y por lo tanto contrastaba con el pequeño televisor con imagen en blanco y negro. Las películas Cinemascope también aumentaron la sensación de telepresencia. Televisión de alta definición, que combina una imagen grande, de alta calidad con sonido de buena calidad, es una extensión de este concepto en el domicilio privado. Kaya -Mutlu pensó que, aunque parece ser nada más que una versión de alta resolución de la 2DTV ordinarias, la televisión de alta definición podría ser un rival para 3DTV en el mercado interno. (Ozaktas, H.M., 2008:608-609). 
La alta definición es una tecnología que no requiere que el usuario utilice artilugios como las gafas para poder ver imágenes de gran calidad y gran realismo visual. La alta definición se está implantando, aunque con un ritmo menor de lo esperado. Según el Censo de Salas de Cine de AIMC (Asociación para la investigación de Medios de comunicación), el número de salas digitales se mantiene estable desde 2009, y en 2012 las salas con proyector digital ya son 1.608 (el 41,4 \%), (marketing. com, 16/05/2012).También en televisión los canales de alta definición aumentan un $48 \%$ en Europa, en el último año 2011 (SatCesc.com, 29/03/2012).

Por otro lado, como apunta Kaya-Maltu, hay que analizar los usos que se dan a las tecnologías. El uso de la televisión como una mera compañía hace absurdo dar el paso a la tecnología 3D, y O. Sandik, desde un punto de vista muy acertado, se plantea la necesidad de analizar cómo va a encajar una tecnología nueva en la vida de las personas. La tecnología 3D está orientada hacia un público atento y centrado en lo que está viendo, siendo una tecnología que usará un público acostumbrado a los hábitos del $2 \mathrm{D}$ cuyos hábitos de consumo son diferentes, ya que hacen un uso distraído de la televisión. Como dice O. Sandik, por lo menos, se puede argumentar que la popularidad de 3DTV puede depender de un cambio radical en los hábitos televisivos y estilos de la mayoría de los espectadores. (Ozaktas, H.M., 2008:609-610).

Aunque debemos tener en cuenta que ya existen televisores que no necesitan las tan molestas gafas para el visionado en 3D.

Los televisores 3D sin gafas utilizan una especie de lente o filtro especial en la parte superior de la pantalla para conseguir sincronizar las imágenes. Es decir, digamos que sería algo parecido a poner unas gafas gigantes a la pantalla para que varias personas puedan ver el contenido 3D al mismo tiempo, en vez de colocar unas gafas 3D a cada espectador de la sala. (Castillo, J.M., 2011:56).

La empresa holandesa Philips ha dejado de lado esta tecnología al no poder resolver el principal problema, que reside en que el espectador se tiene que quedar muy quieto para poder percibir la profundidad. Este escollo parece haber sido salvado por otras empresas, por ejemplo: 
Hitachi ha lanzado un retroproyector de 10 pulgadas, que muestra imágenes en tres dimensiones, gracias a una tecnología llamada "Integral Photography with Overlaid Projection". Dentro de la caja hay 16 proyectores y un complejo sistema de lentes que sincroniza las imágenes. La visión es perfecta desde casi todos los ángulos, pero tiene únicamente una resolución de $640 \times 480$ puntos, a todas luces insuficiente en la era del FullHD. (...)

Así pues, casi todas las ofertas de televisores $3 \mathrm{D}$ sin gafas exigen que los espectadores se coloquen en ciertos sitios, y que no se muevan demasiado si no quieren perder la sensación de profundidad. El Instituto Fraunhofer está trabajando en una tecnología que podría solucionar este problema, aunque de momento solo se aplicará en monitores de ordenador. Su prototipo incluye unos sensores que miden la posición de los ojos, para servir en todo momento las imágenes necesarias para crear la sensación tridimensional. El espectador podrá colocarse donde quiera, sin perder el efecto profundidad. Claro que eso es perfecto cuando se trata de un solo espectador, pero ¿qué ocurre cuando hay dos o más? Esta es una pregunta para la que los inventores del MP3 aún no tienen respuesta. (Castillo, J.M., 2011:57).

La empresa de Singapur Sunny Ocean Studios parece haber superado todos los escollos, pero hay un problema, y es que los datos tienen que ser editados y procesados mediante una tecnología específica para su visionado. (Castillo, J.M., 2011:58).

Pero, además de los usos y costumbres del espectador de televisión, debemos tener en cuenta otras consideraciones. La más importante es el tema de los contenidos. Si no hay un cambio en los contenidos de la televisión, la tecnología 3D se quedará en una mera anécdota, y el espectador no observará cambios importantes en la forma de ver televisión; por tanto, le puede resultar mucho más cómodo activar la versión $2 \mathrm{D}$ de su aparato receptor y olvidarse de las incómodas gafas necesarias para ver la programación en 3D. 
Una de las cuestiones más importantes planteadas en este contexto fue la de los contenidos. Un conjunto 3DTV no significa nada sin contenido 3D. El contenido es el producto real, el set es sólo el dispositivo necesario para poder verla. Lo que va a ser vendido es el contenido, no el conjunto . Por ejemplo, un CD o DVD típico reproductor cuesta mucho menos que el costo de cualquier CD razonable o colección de DVD. Y para el contenido que se debe haber producido la demanda, que puede venir sólo de los clientes que ya poseen sistemas 3DTV, creando la situación de si fue antes el huevo o la gallina. Por lo tanto, Y. Yardimci especula que incluso si hubiera un pequeño grupo de clientes atraídos por la novedad, e incluso si lo podía apoyar la producción de los conjuntos, ¿se alcanza el umbral necesario para justificar la producción de contenidos? Por otro lado, también Yardimci cita la investigación que muestra que las compras de alta definición de juegos de televisión (HD) se elevaba a un ritmo más rápido que los que reciben la programación de HD. Este fue, paradójicamente, sentando las bases para un auge en la producción de contenidos y por lo tanto la solución al problema de la gallina y el huevo. F. Porikli, por otro lado, observó que una lección aprendida de la aceptación de la televisión de alta definición fue que, sin suficiente contenido, no es realista esperar que la gente haga tal inversión. (Ozaktas, H.M., 2008:610-611).

En este mismo sentido apunta Francisco Campos, aunque consideramos que cuando habla de innovación se equivoca, porque el $3 \mathrm{D}$ no es nada nuevo, aunque sí es nuevo su uso en televisión.

Otra innovación que empieza a extenderse es la de 3D. Tras algunos éxitos en el cine se trata de aplicar a la tecnología de la televisión. Ya se han emitido contenidos de fuerte atractivo popular, pero falta dar el salto de la experimentación a la implantación diaria. Para ello se requiere establecer un estándar que fije los parámetros de emisión 
y recepción. La industria de fabricación ya ha puesto en el mercado algunos modelos. Lo que falta es la extensión por ambas partes: por la producción y emisión y por la de los fabricantes de receptores. También en este caso se requieren otros contenidos y tratamientos específicos. Puede ser otra base para replantear el futuro posterior a la crisis. (Campos, 2011:292).

Los contenidos, por tanto, serán lo que den un valor añadido a la tecnología 3D, la espectacularización de los acontecimientos será la que eleve la tecnología esteroscópica a los cielos o la hunda en el olvido más profundo una vez más, en esta ocasión en el ámbito de la televisión. El contenido, más que el continente, es lo que puede hacer resurgir el seguimiento de la audiencia. Antena $3 \mathrm{TV}$, el pasado año realizó un concurso entre varias universidades españolas para que le dieran ideas de cómo llegar a una franja de público más amplia, cómo hacer más atractivo el contenido de su telediario. Cómo cambiar el continente sin cambiar el contenido, muchas fueron las propuestas, algunas de ellas aceptadas como la inserción de las redes sociales, pero lo que se tiene que producir realmente es un cambio en el modo de contar las noticias, para que estas sean atractivas, puesto que la información podemos encontrarla en la red a raudales, sin necesidad de estar pendientes de una hora y un receptor de televisión para tenerla. En este camino trabajan LG, Sansumg y Philips, que se han apuntado al carro de la Televisión Inteligente (o Smart TV). Esta tecnología integra internet y las características Web 2.0 a la televisión digital. Este nuevo concepto de aparato de televisión permite al usuario una gran conectividad con contenidos dentro y fuera de su red local, televisión a la carta, control remoto desde dispositivos móviles, redes sociales, aplicaciones, etc., buscando, sin duda, elevar el grado de interactividad del espectador con aquellos operadores que proporcionen nuevos y atractivos contenidos.

De hecho, la interactividad es una cualidad muy bien valorada por el público. Pero, ¿puede haber interactividad con la tecnología 3D? El espectador puede meterse mucho más en lo que está viendo, puede imaginarse, por ejemplo, en el campo de fútbol jugando o animando a su 
equipo favorito, pero, ¿puede tocar aquello que está viendo? Virtualmente, cree que sí, pero físicamente puede quedarse sin aparato receptor cuando el apasionamiento llegue a límites extremos.

Por otro lado, está el asunto de los costes de producción y de adquisición de receptores. Cambiar las formas de producción de contenidos, nuevos o no, requiere un gran esfuerzo económico por parte de las empresas televisivas que, al día de hoy, no es rentable realizar. Del mismo modo, el usuario debe realizar otro cambio de aparatos receptores, cuando tiene muy reciente el cambio que supuso el apagón analógico en España.

Según revela "The Indie Training Fund Open Forum", la viabilidad empresarial de TV 3D es muy discutible en estos momentos, ya que la producción de contenidos de TV en 3D puede llegar a multiplicar por tres los costes de una producción tradicional. (Bort, I.; García, S. y Martín, M., 2011:347).

Por otra parte, un claro indicador de lo que supone el auge de la TV 3D es la venta de televisores en Espańa. En 2010, las ventas se han incrementado un $20 \%$ respecto a 2009 , con un total de 6,6 millones de televisores vendidos, de los cuales un $70 \%$ son televisores de alta definición, pero una pequeńa parte, el $1 \%$, son HDTV 3D (Gallego, 2010). También hay que tener en cuenta que el mercado de venta de televisores se ha visto dinamizado por el apagón analógico de abril de 2010, y la generalización de la TDT. Las perspectivas de crecimiento para 2011 no son, en este sentido, tan optimistas, ya que la desaceleración económica en España es realmente muy significativa, y el mercado no da síntomas de recuperación. (Bort, I.; García, S. y Martín, M., 2011:348).

\section{Conclusiones}

Como vemos, la televisión 3D ya es una realidad, existe la tecnología, los usuarios tienen acceso a receptores de televisión que soportan la tecnología 3D, y algunas emisoras de televisión ya se plantean retransmitir algunos eventos en $3 \mathrm{D}$. Otro tema será si es rentable dar el paso definitivo 
al 3D, teniendo en cuenta el coste de la producción en este formato. Otro escollo para la implantación del 3DTV está en el ancho de banda necesario para su transmisión, cuando está internet de por medio que puede distribuir la señal más eficientemente.

Consideramos que el futuro está en la unión de internet con la televisión, un hecho que ya está en nuestros hogares; no obstante, tendremos que ver si los investigadores dan con la tecnología necesaria para transmitir, de una forma rentable y cómoda, información 3D sin necesidad de intermediarios (gafas u otros utensilios), con una calidad aceptable.

Por otro lado, está el tema de los contenidos. Mientras la industria cinematográfica y televisiva no sea capaz de generar nuevos contenidos, estaremos ante más de lo mismo, y realizando un desembolso de dinero extra para adquirir las nuevas tecnologías.

La crisis económica y el reciente apagón analógico, que obligó a los usuarios a cambiar sus receptores de televisión o adaptarlos mediante un sintonizador, han hecho que los consumidores sean reacios a adquirir más tecnología sin un valor añadido significativo y una comodidad adecuada.

\section{$\underline{\text { Referencias }}$}

Armenteros, M. (2011). "3D estereoscópico". Madrid: E---Archivos Universidad Carlos III de Madrid.

Bort, I.; García, S. y Martín, M. (eds.) (2011)-“El mercado de la imagen 3D. Un análisis desde la perspectiva de las empresas de comunicación", Actas del IV Congreso Internacional Sobre Análisis Fílmico. Nuevas tendencias e hibridaciones de los discursos audiovisuales en la cultura digital contemporánea, Universitat Jaume I, Castellón. Ediciones de las Ciencias Sociales de Madrid ISBN-978-84-87510-57-1

Campos Freire, F. (coord.) (2011): El Nuevo escenario mediático, Zamora, Espańa, Comunicación Social, ediciones y publicaciones. ISBN-978-84-92860-63-0 
Castillo Pomeda, J.M.- "La televisión estereoscópica: ¿`uturo perfecto o huida hacia delante?", Comunicación y Hombre, 7 (2011) 42-60 ISSN: $1885-365 \mathrm{X}$

EFE (08/05/2012): Terra presenta plataforma para cobertura en Londres y anuncia transmisión 3D, en http://feeds.univision.com/ feeds/article/2012-05-08/terra-presenta-plataforma-para-cobertura Consultado 14/05/2012 Consultado 14/05/2012

Gómez, H. (09/04/2010): Las ventas de televisores 3D alcanzarán los 27 millones de unidades en 2013, en http://www.idg.es/dealerworld/ Las-ventas-de-televisores-3D-alcanzaran-los-27-millones-deunidades-en-2013/seccion-mercado/noticia-92594 Consultado $29 / 11 / 2012$

Lavanguardia.es (14/08/2012): Los Juegos Olímpicos de Londres, aliados con la última tecnología, en http://www.lavanguardia. com/tecnologia/20120814/54337329410/los-juegos-olimpicosde-londres-aliados-con-la-ultima-tecnologia.html Consultado 28/11/2012.

Lgblog (2012): Por primera vez en la historia podrás disfrutar de los Juegos Olímpicos en 3D, en http://lgblog.es/juegos-olimpicos-londres2012-3d-cinema-3d-smart-tv-de-lg/ Consultado 28/11/2012.

Marketing/directo.com (2012): "Las salas de cine digitales y 3D ganan terreno en España, según la AIMC, http://www.marketingdirecto. $\mathrm{com} /$ actualidad/medios/las-salas-de-cine-digitales-y-3d-gananterreno-en-espana-segun-la-aimc/ Consultado 16/05/2012

Nota de Prensa de Panasonic, Barcelona, 24 de mayo de 2011. Disponible en http://www.panasonic.es/html/es_ES/7585762/ index.html, Consultado 14/05/2012

Ozaktas, H.M. (2008): “Three-dimensional Television: Consumer, Social, and Gender Issues", en Ozaktas, H.M. y Onural, L (cords.) ThreeDimensional Television. Capture, Transmission, Display, Ankara, Turkey, Springer-Verlag Berlin Heidelberg. ISBN-3-540-72532-6

Ozaktas, H.M. y Onural, L. (2008): Three-Dimensional Television: From Science-fiction to Reality, en Ozaktas, H.M. y Onural, L (Eds.) Three-Dimensional Television. Capture, Transmission, Display, Springer-Verlag Berlin Heidelberg, Ankara, Turkey. ISBN-3-54072532-6 
Panoramaaudiovisual.com: Panasonic convence en los primeros Juegos Olímpicos en 3D, en http://www.panoramaaudiovisual. com/es/2012/08/06/panasonic-convence-en-los-primeros-juegosolimpicos-en-3d/ Consultado 28/11/2012.

Prensa RTVE (31/07/2011) TVE realiza la primera prueba técnica en 3D a nivel nacional, en http://www.rtve.es/rtve/20110731/tve-realizaprimera-tecnica-3d-nivel-nacional/451265.shtml Consultado el 14/05/2012. Consultado 14/05/2012

Sánchez, C.A. (06/04/2012): Los Juegos Olímpicos de Londres se podrán ver en $3 \mathrm{D}$ gracias a Eurosport, ADSL ZONE en http:// www.adslzone.tv/2012/04/06/los-juegos-olimpicos-de-londres-sepodran-ver-en-3d-gracias-a-eurosport/ Consultado 14/05/2012

SATCAS.COM (2012): "Los canales de alta definición aumentan un 48\% en Europa en el último año, http://satcesc.com/web/2012/03/29/ los-canales-en-alta-definicion-aumentan-un-48-en-europa-en-elultimo-ano/ Consultado 14/05/2012

SATCAS.COM: http://satcesc.com/web/2012/02/16/la-bbcemitira-los-juegos-olimpicos-de-londres-2012-en-3d/Consultado $14 / 05 / 2012$

TerraTV: Natación 3D: súbase al récord de la holandesa Ranomi, en http://deportesar.terra.com.ar/olympic-games/london-2012/ videos/watch/natacion-3d-subase-al-record-de-la-holandesaranomi-412824 Consultado 28/11/2012.

Venta de televisores 3D

http://www.idg.es/dealerworld/Las-ventas-de-televisores-3Dalcanzaran-los-27-millones-de-unidades-en-2013/seccion-mercado/ noticia-92594

h t tp://www.elmundo.es/elmundo/2010/06/10/ navegante/1276152219.html 